Monatsschrift f. Geburtshülfe u. Gynäkologie 1936;102:128

\title{
Hochschul-und Tagesnachrichten
}

Berlin. Kraft Gesetzes wurde wegen Erreichung der Altersgrenze mit dem 31. März 1936 der Geheime Med.-Rat Prof. Dr. Walter Stoeckel von den amtlichen Verpflichtungen entbunden. Geheimrat Prof. Dr. Stoeckel wird sein Amt bis auf weiteres noch vertretungsweise weiterführen.

Prof. Dr. G. A. Wagner ist von der Kaiserlich-Leopold.-Carolin. Deut-schen Akademie der Naturforscher zum Mitglied ernannt worden.

Leipzig. Der n. b. a. o. Professor für Geburtshilfe und Gynäkologie, Dr. Konrad Heim, ist beauftragt worden, im Sommersemester 1936 die Vertretung der durch das Ausscheiden des Prof. Sellheim freigewordenen Professur für genanntes Fach wahrzunehmen.

Wien. Die im Herbst 1934 geschlossene I. Frauenklinik ist Mitte Februar wieder in Betrieb genommen. Vorstand ist Prof. II. Kahr. Die Bundeshebammenlehranstalt wird mit der Klinik verbunden.

Zum a. o. Professor für Geburtshilfe ist der Priv.-Doz. Dr. Пeinrích Kahr ernannt worden. Die Nordostdeutsche Gesellschaft für Gynäkologie und Geburtshilfe ernannte anläßlich ihrer 88. Tagung in Königsberg am 15. Februar 1936 folgende Herren zu Ehrenmitgliedern: 1. Geh. Rat Prof. Dr. W. Stoeckel, Berlin, 2. Prof. Dr. II. Fuchs, Danzig, Direktor der Staatlichen Frauenklinik, 3. Frauenarzt Dr. Erich Radíke, Königsberg. 